\section{A fluorescent technique for demonstrating treponemes in films made from suspected chancres}

\author{
M. F. GARNER AND J. H. ROBSON From the \\ Institute of Clinical Pathology and Medical \\ Research, Department of Public Health, Sydney, \\ Australia
}

A fluorescent technique for demonstrating treponemes in films made from suspected chancres is described. Essentially, this is a reversal of the fluorescent treponemal antibody (FTA-200) test (Wilkinson and Rayner, 1966). The method has been found to be a satisfactory substitute for dark-ground examination of chancre fluid. As in the dark-ground examination method the technique aims to do no more than demonstrate treponemes morphologically indistinguishable from Treponema pallidum. It has the advantage, however, of enabling the medical practitioner, who has no facilities to carry out a darkground examination in the surgery, to prepare a slide from a suspected chancre, fix it, and send it to the laboratory for examination.

\section{METHOD}

Thin films of exudate from suspected chancres were made on glass slides, allowed to dry at room temperature, and then fixed for 10 minutes in acetone. At this stage they were suitable for packaging and sending to the laboratory. In the laboratory the slides were stored at $-20^{\circ} \mathrm{C}$. until tested. On removal from the deep freeze the slides were thawed on the bench at room temperature. They were then carefully wiped, avoiding the area of the film, and allowed to dry at room temperature, after which the area of the specimen was outlined with a diamond stylus. A human serum which was known to have given maximal $(++++)$ fluorescence with the F.T.A.-200 test was inactivated at $56^{\circ} \mathrm{C}$. for 30 minutes, diluted 1 in 200 in phosphate-buffered saline $p \mathrm{H} 7 \cdot 2$, and applied over the whole area of the film. The slides were placed in a moist chamber at $35^{\circ} \mathrm{C}$. for one hour. The excess serum was removed by washing the slides in normal saline and then soaking them in two changes of phosphate-buffered saline each for five minutes. The slides were next dipped into distilled water and carefully wiped dry avoiding the area of the film. Antihuman globulin, labelled with fluorescein isothiocyanate, was diluted to optimum titre in $0.04 \%$ Evans Blue in phosphate-buffered saline. Sufficient of this was placed on each film to cover it completely. The slides were placed in a moist chamber and incubated at $35^{\circ} \mathrm{C}$. for half an hour. They were then washed in normal saline, soaked in phosphate-buffered saline as before and rinsed in distilled water. They were wiped dry, carefully avoiding the film area which was allowed to air dry. The slides were mounted in a mixture Received for publication 8 June 1967.

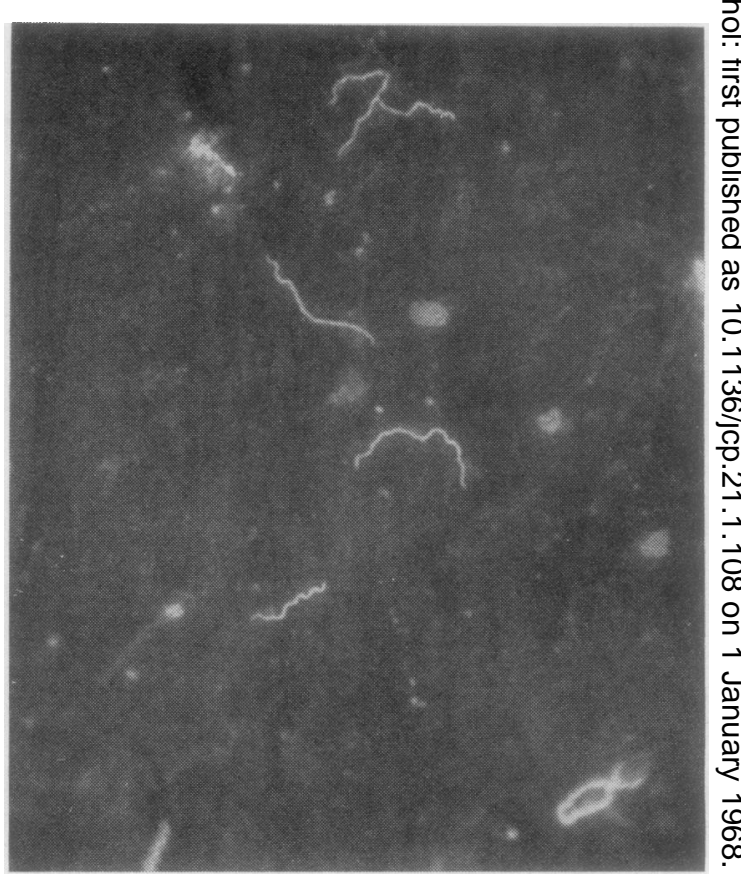

Treponemes, demonstrated by the fluorescent technique described, in a smear made from chancre exudate 1060

of 9 parts glycerine and 1 part phosphate-buffered saline. Results were read using a Leitz Ortholux binocular microscope fitted with $\times 10$ eyepieces, $\times 40$ dry objective, and a dark-ground condenser. An ultraviolet inert oil was used on the dark-ground condenser. The tube factor was 1.25 giving a final magnification of 500 diameters. The ultraviolet light source was an HBO-200 high pressure mercury vapour lamp. The filter combination used consisted of BG38, BG12, and an ultraviolet absorbing filter in the base of the microscope tube. Treponemes, if present, were readily seen as they exhibited a bright a.pple-green fluorescence, i.e., maximum $(+t-++)$ fluorescence (Fig. 1).

\section{COMMENT}

Difficulty was experienced with this test initially due to the thickness of the films made from the exudate from chancres. In our experience a thin film, the thinner the better, was essential. It should be thin enough for newspaper to be easily read through it. In a thick film debris on the slide gave off so much non-specific background fluorescence that it was impossible to see any treponemes. Background fluorescence, though still present in thin films, can be largely eliminated by the use of $0.04 \%$ Evans Blue as recommended by Fry and Wilkinson (1963).

It must be emphasized that this is not a specific technique for demonstrating Treponema pallidum in exudate from chancres. It is a convenient method and has certain advantages in areas where facilities for dark-ground examination are lacking. It can be used to demonstrate, ₹ $\stackrel{1}{\Omega}$

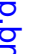

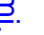
을 


\section{Recovery of human foetal liver cells after storage in liquid nitrogen}

A. J. ZUCKERMAN, H. E. M. KAY, AND A. B. HOCKLEY From the London School of Hygiene and Tropical Medicine and the Royal Marsden Hospital, London

It has now been firmly established that the storage of tissue culture cells in liquid nitrogen at a temperature range of $-150^{\circ} \mathrm{C}$. to $-195^{\circ} \mathrm{C}$. largely prevents deterioration due to thermodynamic changes (Nagington and Lawrence, 1962). Recently a method of culturing fully differentiated human embryo hepatocytes was developed (Zuckerman, Tsiquaye, and Fulton, 1967). We now describe the methods for the preparation of the liver for preservation in liquid nitrogen and for the recovery of the liver cells after thawing.

Livers were obtained by the tissue bank of the Royal Marsden Hospital, after abdominal hysterotomy, from human embryos in whom there was no suspicion of infection in the mother or the foetus. The age of the embryos varied from 8 to 20 weeks. The livers were placed in medium 199 and transferred to the laboratory on melting ice. Disaggregation of the liver cells was carried out by gentle trypsinization with $0.25 \%$ trypsin at room temperature. After inactivation of the trypsin by the addition of calf serum to give a final concentration of $20 \%$ serum in the cell suspension, the cells were centrifuged at 500 r.p.m. at $4^{\circ} \mathrm{C}$. for five minutes. The packed cells were washed once in the growth medium made up with Eagle's minimum essential medium, $10 \%$ foetal calf serum, $0 \cdot 15 \%$ sodium bicarbonate, 100 units $/ \mathrm{ml}$. penicillin, and $100 \mu \mathrm{g} . / \mathrm{ml}$. streptomycin. The cells were resuspended in the growth medium and transferred to the tissue bank on melting ice for storage in liquid nitrogen.

At the tissue bank the suspensions were centrifuged at 500 r.p.m. at $4^{\circ} \mathrm{C}$. for five minutes. Half of the suspending

Received for publication 24 May 1967.

A fluorescent technique for demonstrating treponemes in films made from suspected chancres-concluded

as does the dark-ground method, the presence of treponemes morphologically indistinguishable from Treponema pallidum. The final diagnosis of syphilis rests, as it does in the dark-ground examination, on a combination of history, a sore, and the presence of treponemes.

This paper is published with the approval of the Director-General of Public Health, New South Wales.

\section{REFERENCES}

Fry, C. S., and Wilkinson, A. E. (1963). Brit. J. vener. Dis., 39, 190. Wilkinson, A. E., and Rayner, C. F. A. (1966). Ibid., 42, 8. medium was removed and replaced with cold medium 199 containing $20 \% \mathrm{~V} / \mathrm{V}$ dimethyl sulphoxide, to give a final concentration of $10 \%$ sulphoxide. The cell suspension was transferred in aliquots of 2.0 to $2.5 \mathrm{ml}$. to polyethylene ampoules, which were then heat-sealed and cooled at controlled rates. The apparatus used is similar to that previously described (Pegg, 1966) and depends upon cold alcohol $\left(-79^{\circ} \mathrm{C}\right.$.) being mixed in controlled quantities with the alcohol in which the ampoules are immersed. The programme of cooling is set by a rotating cam and the quantity of injected cold alcohol is determined from moment to moment by a comparison of the actual temperature of the ampoules with the temperature set by the cam.

The rate of cooling was $1^{\circ} \mathrm{C}$. per minute from $5^{\circ} \mathrm{C}$. to $-15^{\circ} \mathrm{C}$., and $5^{\circ} \mathrm{C}$. per minute between $-15^{\circ} \mathrm{C}$. and $-50^{\circ} \mathrm{C}$. The ampoules were transferred to a liquid nitrogen container and stored in nitrogen vapour $\left(-160^{\circ} \mathrm{C}\right.$.) for periods varying between two and seven weeks. When required, the ampoules were removed from the container and placed in a water bath at $40^{\circ} \mathrm{C}$. Gentle agitation ensured complete, rapid thawing in two to three minutes. As soon as the last piece of solid 'ice' had disappeared the ampoules were placed on melting ice and sent to the tissue culture laboratory.

The ampoules were opened on arrival, and the suspen-

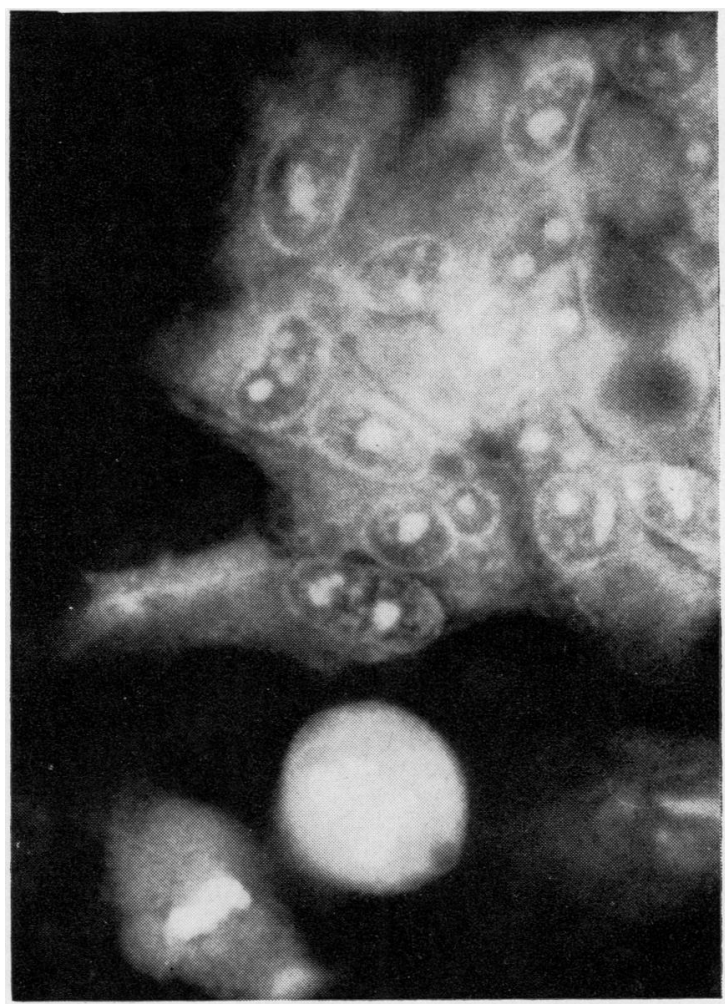

FIG. 1. Human foetal liver cells after recovery from storage in liquid nitrogen. Two mitotic figures are present on the lower margin of the culture. 48 hours in culture. $\times 900$. 